\title{
The chemistry of aluminium in the gastrointestinal lumen and its uptake and absorption
}

\author{
BY J. J. POWELL AND R. P. H. THOMPSON \\ Gastrointestinal Laboratory, The Rayne Institute, St Thomas' Hospital, London SE1 7EH
}

A large number of experimental studies have been carried out on the intestinal absorption and/or uptake of $\mathrm{Al}$, and on the factors that affect this. However, apart from the well-known problems of contamination and the difficulty of analysis of $\mathrm{Al}$, many of these studies have been flawed, particularly when experimental solutions have been used, since often it has not been realized that the Al has precipitated at physiological $\mathrm{pH}$. Other problems have included inappropriate use of buffers (such as containing phosphate) and extrapolation of results from unphysiologically high levels to dietary levels.

Here we shall assess the chemistry, uptake and absorption of $\mathrm{Al}$ from the gastrointestinal tract, and in particular consider the importance of dietary, rather than pharmacological, levels to which the general population is exposed.

\section{CHEMISTRY OF ALUMINIUM IN THE GASTROINTESTINAL TRACT}

There are few reports of the fate of $\mathrm{Al}$ along the lumen of the gastrointestinal tract other than that $\mathrm{Al}$ is very poorly absorbed and its absorption can be interfered with by dietary cofactors. Present theory (Stewart, 1989; Lote \& Saunders, 1991) suggests that most ingested forms of $\mathrm{Al}$ are at least gradually soluble in acid, so some $\mathrm{Al}$ will be solubilized in the chlorhydric stomach after ingestion. When stomach contents reach the duodenum they would be rapidly neutralized by the pancreatico-biliary secretions, and any soluble Al would then precipitate as the hydroxide or co-precipitate as the hydroxide-phosphate and become unavailable for absorption. The small amount that is absorbed is either through the gastric mucosa or immediately before precipitation in the proximal small bowel. This theory explains the poor absorption of ingested $\mathrm{Al}$, the efficacy of $\mathrm{Al}$ compounds as oral phosphate binders and why certain ligands, such as citrate, that can maintain $\mathrm{Al}$ in a soluble form at about neutral $\mathrm{pH}$, may promote absorption of the metal (Weberg \& Berstad, 1986).

Nevertheless, only one study has been performed, in the perfused rat, to demonstrate this (Partridge et al. 1989), and unfortunately abnormally high levels of the metal were used, probably not even representative of the amount of Al solubilized from pharmacologically ingested doses. Many other metals, such as $\mathrm{Cu}, \mathrm{Fe}$ and $\mathrm{Zn}$, precipitate at neutral $\mathrm{pH}$ and yet are better absorbed than $\mathrm{Al}$. This is because they interact with endogenous ligands in gut secretions that maintain these metals in solution during their transit through the bowel (Gollan et al, 1971; Rudzki et al. 1973). Citrate (Piper et al. 1967), lactate (Piper et al. 1967; Powell et al. 1990), pyruvate (Piper et al. 1967), albumin (Oppenheim, 1970; Clemente et al. 1971) and lactoferrin (Dipaola \& Mandel, 1980; Nicolai et al. 1984) are all present in intestinal secretions and could similarly prevent precipitation of dietary $\mathrm{Al}$ during transit. In addition, the binding of trivalent metals, in particular Fe(III), to mucus glycoproteins (mucins) has been investigated since these are 


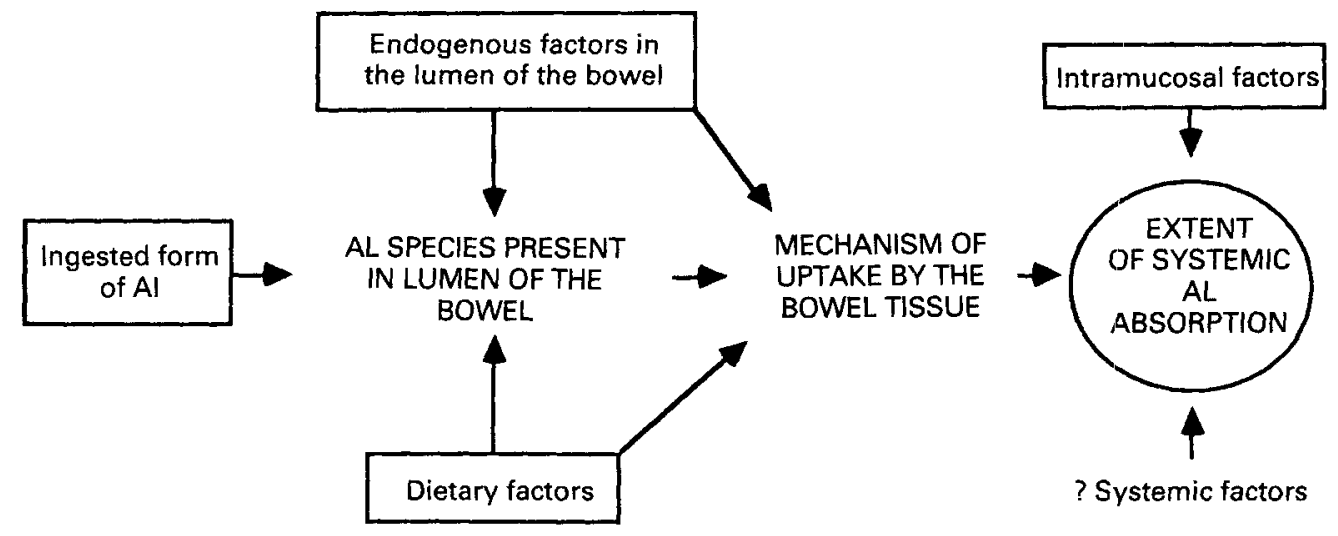

Fig. 1. Four main factors affect the gastrointestinal absorption of $\mathrm{Al}(\square)$. The chemical speciation of $\mathrm{Al}$ in the lumen of the bowel is affected by three of these factors, and is of major importance in determining the mechanism, and so extent, of absorption of Al.

generally bound in preference to divalent metals (Rudzki et al. 1973; Crowther \& Marriott, 1984; Conrad et al. 1991). Although the dissociation constant for Fe (III) binding to mucin is comparatively weak, the total capacity of mucin is high and overall uptake, therefore, efficient (Conrad et al. 1991). Fe(III) binds either directly to isolated mucin (Conrad et al. 1991) or its precipitation is interrupted by stabilization of colloidal sized hydroxy-Fe species bound to the glycoprotein (Rudzki et al. 1973). Al also binds to mucus glycoproteins, at least at acid $\mathrm{pH}$ (Crowther \& Marriott, 1984), probably via sialic acid end-groups, but this interaction has not been fully studied, so direct interaction with monomeric $\mathrm{Al}$, or stabilization of a polymeric, perhaps colloidal, species are both possible. Hence, the solution chemistry of dietary $\mathrm{Al}$ in the lumen of the gastrointestinal tract will be dictated by competition from endogenous factors, such as mucins, albumin and citrate, and, exogenous (dietary) factors.

Many experimental studies have shown a large uptake of $\mathrm{Al}$ by the gut but then little absorption (Feinroth et al. 1982; Farrar et al. 1988; Van der Voet et al. 1989). The relative percentages of this $\mathrm{Al}$ that are intramucosal and extramucosal have not been elucidated but our own work suggests that at least the latter (i.e. adhesion onto gut mucosa) is one major limiting factor to $\mathrm{Al}$ absorption (Powell \& Thompson, 1990). This barrier may be largely derived from the overlying insoluble mucus, which avidly binds metals (Quarterman, 1987). Transport of metals through mucus is not understood but fasting increases the absorption of $\mathrm{Zn}$ and $\mathrm{Fe}$ from the diet (Quarterman, 1987), probably due to an increase of sialic acid residues within the mucus overlying the mucosal surface (Quarterman, 1987). Fasting may similarly, therefore, increase the systemic absorption of $\mathrm{Al}$, as has been suggested from findings with $\mathrm{Ga}$ (Farrar et al. 1988), used as a proxy for $\mathrm{Al}$.

Thus, under typical dietary situations, the $\mathrm{Al}$ species formed in the lumen, and at the mucosal surface of the gastrointestinal tract determine the efficiency of absorption of the metal (Fig. 1). These have not been well studied, but clearly the limited absorption of $\mathrm{Al}$ from the diet is due to more complex reasons than rapid precipitation in the lumen. 


\section{SITE OF ABSORPTION}

It has often been suggested that $\mathrm{Al}$ is mainly absorbed from the stomach (Kaehny $e t$ al. 1977; Fleming et al. 1989), based on the hypotheses that Al should only be soluble in the acid stomach and precipitate at neutral $\mathrm{pH}$ of the bowel; in vivo, however, such precipitation is unlikely. The stomach has a small absorptive area and, at least in the rat, the absorption of Al with citrate occurs from the proximal small bowel (Froment $e t$ al. 1989a). In man, oral-dosing experiments with antacids and citrate (Weberg \& Berstad, 1986) show a peak $\mathrm{Al}$ concentration in blood at $4 \mathrm{~h}$, suggesting small bowel absorption, since experiments with bismuth citrate-containing compounds achieve peak bismuth concentrations by $30 \mathrm{~min}$ (Nwokolo et al. 1989), mainly due to absorption from the most proximal small bowel (Nwokolo et al. 1989) or some as particles in the stomach (Nwokolo et al. 1992). It seems likely, therefore, that Al absorption occurs from the small bowel and not normally from the stomach, although a few metal-containing particles of nanometer diameter are able to penetrate the gastric mucosa (Nwokolo et al. 1992). Finally, we have shown that the intestinal lymphoid aggregates (ILA) of the distal bowel in man contain large quantities of sub-micron-sized aluminosilicates (Powell et al. 1991) that are almost certainly dietary derived. The role of ILA, which have luminal scavenging activity, requires assessment in disease and perhaps also in the absorption of Al.

\section{MECHANISMS OF ABSORPTION}

A number of mechanisms for the absorption of Al have been suggested, but often with poor interpretation of the data. For example, Provan \& Yokel (1988) suggested from the effects of various channel-blocking compounds that $\mathrm{Al}$ uptake occurs by an energyindependent, Na-dependent, paracellular pathway-mediated process. However, the results more probably showed the effect of various chemicals on a precipitate of $\mathrm{Al}$ and its adherence to mucus and mucosa.

$\mathrm{Ca}$ inhibits $\mathrm{Al}$ absorption and some have postulated, therefore, that $\mathrm{Al}$ may share the $\mathrm{Ca}$ absorption process (Lote \& Saunders, 1991). This is unlikely, since the small size of the $\mathrm{Al}$ ion will not favour substitution for the larger $\mathrm{Ca}$ ion (MacDonald \& Martin, 1988), and the effect of Ca may rather be better maintenance of the paracellular pathway (Froment et al. 1989a). The size of the $\mathrm{Al}$ ion is more like that of $\mathrm{Fe}$ (III) and $\mathrm{Mg}$ ions (MacDonald \& Martin, 1988); but in the rat, Fe(II), and not Fe(III) increases the intestinal uptake and reduces the absorption of $\mathrm{Al}$ (Van der Voet \& de Wolff, 1987). These latter findings, however, are difficult to interpret since the bowel was perfused at unphysiologically low $\mathrm{pH}(\mathrm{pH} 3)$ and high rate of flow $(10 \mathrm{ml} / \mathrm{min})$; moreover, the speciation of $\mathrm{Fe}$ (III) is uncertain even at this low $\mathrm{pH}$. Absorption of $\mathrm{Fe}$ (III) probably does not occur actively but instead it is reduced to Fe(II) at the mucosa and is then actively absorbed (Raja et al. 1991). However, the size and charge of the Al ion are significantly different from those of $\mathrm{Fe}(\mathrm{II})$ and so $\mathrm{Al}$ is unlikely to follow this uptake mechanism. The dependence on body Fe status of the systemic transfer of $\mathrm{Al}$ is discussed later. Although interactions with intestinal $\mathrm{Mg}$ transport have not been studied, the minute absorption of $\mathrm{Al}$ and its increase by the concomitant ingestion of citrate (Weberg $\&$ Berstad, 1986) do not support its use of an active transport system.

Passive absorption may occur either between enterocytes (paracellular) or through enterocytes (transcellular). Al in the presence of citrate appears to be largely absorbed 
by the paracellular pathway through imperfect tight junctions (Froment et al. 1989a), probably because citrate chelates intramucosal $\mathrm{Ca}$. Not all $\mathrm{Al}$ absorption necessarily occurs in this manner, since the $\mathrm{Al}$ species present in the lumen of the gastrointestinal tract will dictate how it is taken up by the mucosa. Other potential routes of uptake include persorption (O'Hagan, 1990; paracellular), endocytosis by mucosal cells (O'Hagan, 1990; transcellular) or conventional transcellular transport of hydrophobic or very small hydrophilic species. It is unclear which of these mechanisms predominates for Al in a normal diet.

\section{ABSORPTION OF ALUMINIUM FROM THE GASTROINTESTINAL TRACT IN THE NORMAL POPULATION}

A number of patient groups with hyperpermeability of the bowel may be particularly at risk of hyperabsorption of $\mathrm{Al}$. These include patients with renal failure (Lindholm et al. 1985), who have more permeable guts (Magnusson et al. 1991), infants (Weaver et al. 1984; Bishop et al. 1989) and those with enteropathy (Lindholm et al. 1985). However, the first sound evidence of gastrointestinal absorption of $\mathrm{Al}$ from normal volunteers was that of Kaehny et al. (1977) by analysis of plasma and urine levels after dosing with different Al compounds. This work used a relatively contaminant-free collection procedure and a sensitive analytical technique (furnace atomic absorption spectrometry), since baseline levels of plasma were quite low $(6-7 \mu \mathrm{g} / \mathrm{l})$. Nevertheless, it was not possible to estimate precisely the amount absorbed because only one elimination route (urine) was studied. A full balance study was then attempted in six men using Al-containing antacids (Gorsky et al. 1979). Typically this work is difficult because such a tiny percentage of the $\mathrm{Al}$ is absorbed, because of problems with exogenous contaminating $\mathrm{Al}$, either in the diet or during sample collection, and because of the need for highly accurate analyses. The results suggested an apparent positive balance of $23-330 \mathrm{mg} \mathrm{Al} / \mathrm{d}$ during the ingestion phase (Gorsky et al. 1979), in agreement with previous work with $\mathrm{Al}$ balances in uraemic patients given large oral loads of Al (Clarkson et al. 1972). Clearly these results were gross overestimates of normal retention, either attributable to the problems discussed previously, or to too short a faecal collection time after dosing. A subsequent balance study (Greger \& Baier, 1983) indicated that any body burden of Al could not be shown within the error of the study, which is probably a fair summary. Interestingly, for subjects ingesting low (i.e. normal) levels of $\mathrm{Al}(5 \mathrm{mg} / \mathrm{d}), 0 \cdot 78 \%$ of this was excreted in the urine, suggesting that at least this small amount is absorbed from the normal diet (Greger \& Baier, 1983). However, the average baseline urinary levels of $\mathrm{Al}$ ( $35 \mu \mathrm{g} / \mathrm{d}$ ) were slightly high compared with those in subsequent studies, which showed average baseline urinary levels per $24 \mathrm{~h}$ of 2.7 and $4.6 \mu \mathrm{g}$ (Haram et al. 1987); $7.56 \mu \mathrm{g}$ (Weberg \& Berstad, 1986); and 9, 12, 29 and $8 \mu \mathrm{g}$ (Walker et al. 1990). These differences may be due to differences in analytical techniques, varying dietary intake, or changes in fluid output, since total urinary Al excretion correlates with urine volume (Greger \& Baier, 1983). Thus, a good fluid output may be necessary to achieve an Al output that approximates to the amount absorbed.

At least $1 \%$ of $\mathrm{Al}$ was absorbed from a dose of $1 \cdot 1 \mu \mathrm{g}$ Al coingested with a sodium citrate solution (Day et al. 1991), measured with the ${ }^{26} \mathrm{Al}$ isotope in blood by high-energy accelerator mass spectrometry. The lower limit of $1 \%$ absorption is based on the peak blood analysis at $6 \mathrm{~h}$, although the peak in blood was probably considerably earlier. 
Furthermore, because urinary analysis of ${ }^{26} \mathrm{Al}$ is more difficult it was not reported, but would have given a better estimate of the lower limit of absorption, which in this study was probably higher than $1 \%$. Nevertheless, an extremely low dose of $\mathrm{Al}$ was used in a sodium citrate solution, and was not designed to mimic the dietary situation. More importantly, this demonstrated the first use of ${ }^{26} \mathrm{Al}$, which should avoid the enormous analytical problems associated with standard ${ }^{27} \mathrm{Al}$ and its background concentrations in the body and diet.

A number of single-dosing studies using standard Al have been carried out in man, mainly with antacids (Weberg \& Berstad, 1986). However, it is then not known how much $\mathrm{Al}$ is in solution in the intestinal lumen and, therefore, even how much is potentially available for absorption. The dissolution of antacids is complex even in vitro (Hem \& White, 1989) and in vivo many physiological factors such as gastric emptying, $\mathrm{pH}$ and transit times will greatly affect the degree of solubility of antacids in the stomach. Nevertheless, the fractional absorption of $\mathrm{Al}$, based again on urinary excretion, was $0.007 \%$ from one antacid tablet $\left(244 \mathrm{mg} \mathrm{Al}(\mathrm{OH})_{3}+45 \mathrm{mg} \mathrm{MgCO}_{3}\right), 0.004 \%$ from four tablets, and $0.001 \%$ from eight tablets (Weberg \& Berstad, 1986). These and other findings (Greger \& Baier, 1983; Day et al. 1991) suggest, not surprisingly, that the fractional gastrointestinal absorption of $\mathrm{Al}$ decreases with increasing dose.

Recent work with non-haem-Fe shows that promoters and inhibitors of absorption (Cook et al. 1991) have markedly less effect in a whole diet than when used in isolated absorption studies and, thus, the availability of $\mathrm{Al}$ from the average diet is probably between 0.1 and $1 \%$ but nearer $0.1 \%$; the lower limit is based on an average urinary excretion of $10 \mu \mathrm{g} / \mathrm{d}$ (Walker et al. 1990) and an intake of $8 \mathrm{mg} / \mathrm{d}$ (Sherlock, 1989), and the upper limit is based on the results discussed previously (Greger \& Baier, 1983; Day et al. 1991).

\section{GASTROINTESTINAL ACIDITY AND THE FORM OF INGESTED ALUMINIUM}

It has been suggested that an acidic environment promotes the absorption of $\mathrm{Al}$, based mainly on results from in situ perfusion of the rat gut (Van der Voet \& de Wolff, 1986). However, this experiment probably rather indicates that at the lower $\mathrm{pH}(\mathrm{pH} 4)$ more $\mathrm{Al}$ is in solution, and so absorbed, than at the higher $\mathrm{pH}(\mathrm{pH} \mathrm{7)}$. This is an oversimplification of the situation in vivo, and, moreover, the effect of acid $\mathrm{pH}$ on the permeability of the bowel mucosa was not investigated.

The instillation in man of antacids suspended in $70 \mathrm{ml} \mathrm{HCl}(\mathrm{pH} \mathrm{2.4)}$ did not affect the absorption of Al (Weberg \& Berstad, 1986), but in contrast when the gastric pH was raised to 5.9 using intravenous ranitidine (Rodger et al. 1991), the absorption of Al from antacids, based on urinary excretion, was greatly reduced. This latter study needs careful interpretation since acidity is required for the dissolution of antacids and again these results probably show that more $\mathrm{Al}$ is solubilized from antacids at the lower $\mathrm{pH}$, and not that acid itself increases the absorption of $\mathrm{Al}$. So there is little evidence to suggest that an elevated proton concentration in the stomach/bowel increases $\mathrm{Al}$ absorption, but rather that, like Fe (Champagne, 1988), a more acidic gastric environment may help to solubilize more of the ingested $\mathrm{Al}$. Clearly the gastric solubility of $\mathrm{Al}$ depends largely on the form in which it is ingested. Aluminosilicates yield little soluble Al even at acidic $\mathrm{pH}$ and $\mathrm{Al}$ from these is not absorbed (Mauras et al. 1983); dissolution and absorption from $\mathrm{Al}(\mathrm{OH})_{3}$ is variable but low (Kaehny et al. 1977; Weberg \& Berstad, 1986), while 
absorption of Al from soluble salts (e.g. chloride, lactate) is slightly higher (Froment et al. 1989 b). The release of endogenous and added forms of $\mathrm{Al}$ from various fluids and foods in the gastric environment has not been studied.

\section{FOOD AND DRINKING WATER}

In spite of the problems associated with epidemiological studies it is interesting that at least seven studies have so far related elevated $\mathrm{Al}$ concentrations in drinking water to an increased rate of Alzheimer's disease (Crapper-McLachan et al. 1991). Can Al from drinking water really be more readily absorbed? The same authors (Crapper-McLachan et al. 1991) postulate that differences between the organic or inorganic forms of $\mathrm{Al}$ should be considered. This seems unlikely. First, Al should be released in the acidic stomach from its waterborne complexes, although due to the slow rates of ligand exchange of the metal and the rapid gastric emptying of fluids, this cannot be assured; second, because the high concentration of endogenous ligands in the bowel will then compete with the generally low concentrations of waterborne organic ligands; and third, because the ligands in water that are generally most avid for Al will reduce its absorption (e.g. fluoride, phosphate, silicic acid). In contrast, some ligands in food may promote the systemic absorption of $\mathrm{Al}$ (e.g. citrate, maltol). An alternative theory (Martyn et al. 1989 ) is that $\mathrm{Al}$ from drinking water is more absorbable because of its easy solubility, compared with that released and solubilized from food in the gastric environment. This is likely to be true, since food buffers acid in the stomach and is probably a poor source of soluble Al. The question of quantity, however, is even more important. Based on the unlikely scenario of the European Community Directive maximum allowed concentration of $\mathrm{Al}$ in water of $200 \mu \mathrm{g} / \mathrm{l}$, a daily ingestion of 2 litres of such water, and an absorption of $1 \%$, then only $4 \mu \mathrm{g}$ will be absorbed per $\mathrm{d}$. This is still less than half the $\mathrm{Al}$ normally excreted in the urine over the same period. Diet, and when applicable drugs, are, therefore, the likely major source of absorbed $\mathrm{Al}$.

A third and more plausible hypothesis (Birchall \& Chappell, 1989) is that these seven epidemiological studies are instead markers of silicic acid intake, since fluids, rather than food, are the major ingested source of $\mathrm{Si}$, and the concentration of silicic acid inversely correlates with the concentrations of $\mathrm{Al}$ in drinking water. Silicic acid may well be protective against the effects of $\mathrm{Al}$, so further epidemiological studies should consider this.

\section{PROMOTERS AND INHIBITORS OF ALUMINIUM ABSORPTION}

\section{Citric acid}

Certain dietary cofactors undoubtedly affect the absorption of $\mathrm{Al}$, although their role in the diet may be considerably less than when studied in isolation. In particular, based on urinary $\mathrm{Al}$ excretion, citric acid promoted the systemic absorption of $\mathrm{Al}$ from antacids by about fiftyfold in one study (Weberg \& Berstad, 1986) and eightfold in another (Walker et al. 1990). Significant increases in plasma Al were also noted (Slanina et al. 1986; Weberg \& Berstad, 1986) after co-dosing citrate and Al, compared with Al alone. The extent of this increase in $\mathrm{Al}$ absorption by citrate will depend on the form of $\mathrm{Al}$ and the concentrations of $\mathrm{Al}$ and citrate. Oral citrate alone only slightly increases serum $\mathrm{Al}$ levels 
(Slanina et al. 1986) or has no effect on the serum levels (Weberg \& Berstad, 1986). Clearly the co-ingestion of both citrate and $\mathrm{Al}$ are required to increase $\mathrm{Al}$ absorption greatly, and there are three possible mechanisms for this effect: (1) Al may be maintained in solution at the neutral $\mathrm{pH}$ of the bowel and, thus more will be available for absorption. This is potentially true for large doses of $\mathrm{Al}$, but with dietary levels although some binding of $\mathrm{Al}$ to citrate in the lumen is a probable consequence of their co-ingestion, it is unlikely to be for the reason of solubility that citrate promotes the absorption of dietary $\mathrm{Al}$, since many other ligands in endogenous secretions perform this task; but rather because aluminium citrate species are small and could then be well absorbed; (2) citrate and Al may form an uncharged species better able to pass the lipophilic gastrointestinal mucosa (Slanina et al. 1986). This seems unlikely, because this species forms only at below $\mathrm{pH} 4$, and predominantly at $\mathrm{pH} 2 \cdot 5$ (Slanina et al. 1986), in other words in the stomach which is an unfavourable site for absorption; (3) citrate may chelate endogenous mucosal $\mathrm{Ca}$ and so make the paracellular pathway of the bowel more accessible by opening the tight junctions between the mucosal cells (Froment et al. $1989 a$ ). This is the more likely explanation of the 'citrate effect', perhaps facilitated by the small size of any aluminium citrate species formed.

\section{Other dietary ligands}

Just as the enhancing action of dietary citrate on absorption may be partly by binding $\mathrm{Al}$ in the intestinal lumen, so other dietary ligands could similarly affect the gastrointestinal uptake of the metal. In principle, ligands must be able to compete with hydroxide, which, at about neutral $\mathrm{pH}$ combines with $\mathrm{Al}$ to precipitate it out as $\mathrm{Al}(\mathrm{OH})_{3}$. In practice, this probably does not happen in the lumen containing dietary levels of $\mathrm{Al}$, because interactions with endogenous ligands maintain Al truly soluble, metastable, or as a stable colloid form. Nevertheless, polymerization of hydroxy-Al species is a strong driving force, so for dietary ligands to be effective they must at least be able to compete with this process and probably with others, such as the interactions of mucus and $\mathrm{Al}$, protein and $\mathrm{Al}$ and the low-molecular-weight ligands and $\mathrm{Al}$. The relative strengths of some typical ligands for $\mathrm{Al}$ can be calculated thermodynamically (Ohman \& Sjoberg, 1988). Al-ligand interactions depend largely on their relative concentrations and $\mathrm{pH}$, but because of kinetic factors and the possibility of the formation of metastable species, thermodynamic calculations are only a guide and cannot give definitive predictions. For example, if the concentration of lactate (relatively strong; Ohman \& Sjoberg, 1988) is favourable, it can compete at least transiently at neutral $\mathrm{pH}$ with hydroxide (very strong; Ohman \& Sjoberg, 1988) by the formation of a metastable species (Corain et al. 1992). The following potential ligands have been studied for their effect on the systemic absorption of $\mathrm{Al}$.

\section{Silicon}

Within our lithosphere $\mathrm{Al}$ is found mainly as inert aluminosilicates. The interaction between $\mathrm{Si}, \mathrm{Al}$ and $\mathrm{O}$ is so strong that even today there are no economical methods for the extraction of $\mathrm{Al}$ from these minerals. However, soluble $\mathrm{Si}$ is available, as silicic acid, theoretically up to $120 \mathrm{mg} / \mathrm{l}$ in water (Carlisle, 1982), and clearly solution chemistry between these elements ( $\mathrm{Si}, \mathrm{Al}$ and O) occurs (Chappell \& Birchall, 1988), if only as a 
precursor to the formation of aluminosilicates. The Si present in food is less available to interact with $\mathrm{Al}$ than that within fluids, for example drinking water, where it is mainly monomeric silicic acid (Birchall \& Chappell, 1989). The concentrations of silicic acid in drinking water varies from $0 \cdot 5-14 \mathrm{mg} / \mathrm{l}$, depending on the origin of the water (Birchall \& Chappell, 1989), so 1 litre of drinking water will yield $18-500 \mu \mathrm{mol}$ silicon. Assuming that as much as $10 \%$ of dietary $\mathrm{Al}(0.8 \mathrm{mg} / \mathrm{d})$ is available in the lumen of the gastrointestinal tract, then the molar ratio of $\mathrm{Si}: \mathrm{Al}$ is up to $30: 1$. This general excess of $\mathrm{Si}$ over $\mathrm{Al}$, particularly at the higher ratios, may be important, since these elements are then able to interact in solution (Chappell \& Birchall, 1988). Furthermore, the solution chemistry is enhanced in the presence of bicarbonate (Chappell \& Birchall, 1988) which is secreted by the bowel and in pancreatic juice. Metastable aluminosilicates may be formed in solution, and these hydroxyaluminosilicates are considerably less available; for example they limit the toxicity of Al to the gills of fish (Birchall et al. 1989), probably by preventing the interaction of $\mathrm{Al}$ with mucus or epithelium (Birchall et al. 1989).

In the gut there is a large number of other chemical species that may interact with $\mathrm{Al}$ and their competition with $\mathrm{Si}$ for $\mathrm{Al}$ is strongly $\mathrm{pH}$ dependent (Birchall, 1990). Intestinal $\mathrm{pH}$ varies in both the lumen and the microclimate of the bowel between $\mathrm{pH} 6$ and $7 \cdot 5$, which is exactly where silicic acid competes well with phosphates and even with citrate (Birchall, 1990). Since oral Si appears to be protective against accumulation of $\mathrm{Al}$ in the ageing brain of the rat (Carlisle \& Curran, 1987), it is, therefore, plausible that dietary Si and $\mathrm{Al}$ interact in the gastrointestinal tract, and so the importance of silicic acid in our diet against other potentially limiting factors, such as phosphate, phytate and polyphenols of tea requires investigation.

\section{Phosphate and phytate}

The stability of $\mathrm{AlPO}_{4}$ and the use of oral $\mathrm{Al}$ compounds (hydroxide and hydroxycarbonate) as phosphate binders (Kaye \& Gagnon, 1985), indicate that $\mathrm{Al}$ and $\mathrm{P}$ form strong complexes. In the gastrointestinal tract, phosphate probably adsorbs onto the positively charged surface of $\mathrm{Al}(\mathrm{OH})_{3}$ or hydroxycarbonates (Liu et al. 1984). In contrast, the adsorption of dietary $\mathrm{Al}$ onto phosphate is less certain, since so many other negatively charged species are available and phosphate with such a large surface area is unlikely to be available.

Solution chemistry between $\mathrm{Al}$ and various phosphates is demonstrable (Goldshmid \& Rubin, 1978), but around neutral $\mathrm{pH}$ a precipitate is dominant (Erdman \& PonerosSchneier, 1989). Thus, similarly to the hydroxide of $\mathrm{Al}$, it is more likely that other endogenous and dietary ligands prevent or interfere with the growth of aluminium hydroxyphosphate species. Furthermore, other cations such as $\mathrm{Ca}$, could compete for phosphate. The expected effect of dietary inorganic phosphate, if at all, is to limit the systemic absorption of $\mathrm{Al}$, but further work with in vivo absorption studies is required.

Phytic acid is the hexaphosphate of myo-inositol and is present in food, particularly cereals (Erdman \& Poneros-Schneier, 1989). It is a strong chelating agent for a number of metal ions (Kratzer \& Vohra, 1986; Erdman \& Poneros-Schneier, 1989) and forms a stable and readily precipitable complex with Fe(III) (Kratzer \& Vohra, 1986). Its interactions with metal ions reduces their bioavailability (Erdman \& Poneros-Schneier, 1989 ) and so its effect on the absorption of $\mathrm{Al}$ also requires study. 


\section{Maltol (3-hydroxy-2-methyl-4 pyrone) and fluoride}

Maltol and fluoride are both dietary agents that form strong complexes with $\mathrm{Al}$ (Ohman \& Sjoberg, 1988). Maltol is used as a flavouring agent in some foodstuffs, and is also a natural product of caramelization. Maltol significantly increases the absorption of oral $\mathrm{Ga}$ (used as a proxy for $\mathrm{Al}$ ) in fasted rats (Farrar et al. 1988), while fluoride decreases it (Farrar et al. 1988). Using everted gut sac experiments, these opposing actions of fluoride and maltol were shown not to be different effects on the uptake by mucosa, but rather on its subsequent transfer (i.e. absorption). Since both maltol and fluoride favour the formation of small $\mathrm{Al}$ complexes, the reason for these differences are not clear but may be related to overall species charge or, again, intramucosal Ca chelation. The average daily intake of fluoride is less than $2 \mathrm{mg} / \mathrm{d}$ (Walters et al. 1983) and so important interactions with $\mathrm{Al}$ in the lumen will be limited.

\section{Other ligands}

$\mathrm{Al}$ in tea infusion is partly bound to polyphenols, possibly thearubigens (Baxter et al . 1989). Although some work has suggested that the absorption of $\mathrm{Al}$ after tea drinking is increased (Koch et al. 1988), this measured total $\mathrm{Al}$ in $24 \mathrm{~h}$ urine and did not take into account the diuretic effect of tea, nor has it been supported in studies with rats (Fairweather-Tait et al. 1991). Tea inhibits the absorption of non-haem-Fe from the diet (Disler et al. 1975; Fairweather-Tait et al. 1991) and it is possible that a similar inhibitory effect on absorption of $\mathrm{Al}$ from other dietary sources is seen when food is taken with tea.

Based on empirical in vitro observations, it has been suggested that a number of low-molecular-weight carboxylates in the diet may bind $\mathrm{Al}$, namely ascorbic, citric, gluconic, lactic, malic, oxalic and tartaric acids (Partridge et al. 1989). These may bind strongly, such as citrate, or induce metastable species, such as lactate and probably ascorbate. Compared with a control group of animals receiving only $\mathrm{Al}(\mathrm{OH})_{3}$, all these ligands increased tissue concentrations, but surprisingly not the urinary output, of $\mathrm{Al}$ when they were separately added to the drinking water of rats similarly receiving $\mathrm{Al}(\mathrm{OH})_{3}$ (Domingo et al. 1991a). Experiments in rabbits (Fulton \& Jeffery, 1990) and man (Domingo et al. 1991b) show that ascorbate increases the urinary excretion of Al. If interaction of these ligands with $\mathrm{Al}$ in the lumen promotes its absorption, then the quantities ingested are important in determining whether they interfere with $\mathrm{Al}$ as it passes through the gastrointestinal lumen. Lactate and ascorbate would need, therefore, to be in greater concentration than citrate to compete for $\mathrm{Al}$. The effects of these ligands on binding Ca should also not be ignored. The overall charge of the species formed is not known, but the small size of the $\mathrm{Al}$ complexes could be an important factor in helping to promote $\mathrm{Al}$ absorption. Finally, even certain large molecules such as lactoferrin need to be considered, since this protein promotes the absorption of a number of metals, for example $\mathrm{Pb}$ (Quarterman \& Morrison, 1985).

\section{Effect of iron status}

Based on the similar chemistry of $\mathrm{Al}$ and $\mathrm{Fe}(\mathrm{III})$, it has been postulated that $\mathrm{Al}$ may share with $\mathrm{Fe}$ some mechanisms of intestinal absorption, and that this may be affected by 
the individual's efficiency of the Fe-absorptive mechanism (Cannata et al. 1984). Although $\mathrm{Al}$ is not related to mucosal uptake of $\mathrm{Fe}(\mathrm{III})$ (see p. 243), its subsequent systemic transfer may be partly modulated by the Fe status of an individual. Fe absorption is itself probably controlled by circulating humoral mediators related to body Fe status (Apte \& Bown, 1969; Conrad, 1969; MacDermott \& Greenberger, 1969) and by intestinal mucosal Fe stores (Conrad \& Crosby, 1963; Adams et al. 1991). Similarly, Fe status (determined by ferritin levels) inversely predicts absorption of Al (Cannata et al. 1984), and this appears to be partly related to Fe status of the intestinal mucosal cells, which in culture take up significantly more Al when Fe-deplete (Menendez et al. 1991). This Fe depletion of mucosal gut cells is probably a risk factor in enhancing the systemic absorption of at least transcellularly entering Al.

\section{CONCLUSION}

Dietary $\mathrm{Al}$ in the lumen of the stomach is composed of a portion that is broken down and solubilized by acid and that which passes down the gastrointestinal tract in its ingested insoluble form. The stomach is not an important site for absorption of $\mathrm{Al}$, which mainly occurs in the small intestine. Solubilized $\mathrm{Al}$ in the small intestine will bind to endogenous intestinal species such as lactoferrin, lactate and mucins. The interaction with mucins may be stoichiometric or only by stabilization of polymeric $\mathrm{Al}(\mathrm{OH})_{3}$; simple precipitation of $\mathrm{Al}(\mathrm{OH})_{3}$ does not occur. Dietary ligands may then compete with these endogenous Al-ligand interactions in the bowel to form other Al species which, depending on the ligand, may promote or further inhibit systemic absorption. Some dietary factors may also have non-ligand effects on absorption of $\mathrm{Al}$, e.g. the chelation of intramucosal $\mathrm{Ca}$ by citrate. $\mathrm{Al}$ is passively absorbed from the bowel and the species of $\mathrm{Al}$ in the lumen and some non-ligand factors will dictate whether the route of absorption is paracellular or transcellular, and thus the efficiency of absorption. The average absorption of $\mathrm{Al}$ from the diet is probably around $0 \cdot 1 \%(10 \mu \mathrm{g} / \mathrm{d})$.

\section{REFERENCES}

Adams, P. C., Zhong, R., Haist, J., Flanagan, P. R. \& Grant, D. R. (1991). Mucosal iron in the control of iron absorption in a rat intestinal transplant model. Gastroenterology $\mathbf{1 0 0}, 370-374$.

Apte, S. V. \& Bown, E. B. (1969). Effects of plasma from pregnant women on iron absorption in the rat. Gastroenterology 57, 126-133.

Baxter, M. J., Burrell, J. A., Crews, H. M. \& Massey, R. C. (1989). Aluminium in infant formulae and tea and leaching during cooking. In Aluminium in Food and the Environment, pp. 77-87 [R. C. Massey and D. Taylor, editors]. London: Royal Society of Chemistry.

Birchall, J. D. (1990). The role of silicon in biology. Chemistry in Britain 26, 141-144.

Birchall, J. D. \& Chappell, J. S. (1989). Aluminium, water chemistry, and Alzheimer's disease. Lancet i, 953.

Birchall, J. D., Exley, C., Chappell, J. S. \& Phillips, M. J. (1989). Acute toxicity of aluminium to fish eliminated in silicon-rich acid waters. Nature 338, 146-148.

Bishop, N., McGraw, M. \& Ward, B. (1989). Aluminium in infant formulas. Lancet i, 565.

Cannata, J. B., Svarez, C., Cuesta, V., Roza, R. R., Allende, M. T., Herrera, J. \& Llanderal, J. P. (1984). Gastrointestinal aluminium absorption: Is it modulated by the iron-absorptive mechanism? Proceedings of the European Dialysis and Transplant Association - European Renal Association 21, 354-359.

Carlisle, E. M. (1982). The nutritional essentiality of silicon. Nutrition Reviews 40, 193-198.

Carlisle, E. M. \& Curran, M. J. (1987). Effect of dietary silicon and aluminium on silicon and aluminium levels in rat brain. Alzheimer Disease and Associated Disorders 1, 83-89. 
Champagne, E. T. (1988). Low gastric hydrochloric acid secretion and mineral bioavailability. In Advances in Experimental Medicine and Biology, vol. 249, Mineral Absorption in the Monogastric GI Tract, pp. 173-184 [F. R. Dintzis and J. A. Laszlo, editors]. New York: Plenum Press,

Chappell, J. S. \& Birchall, J. D. (1988). Aspects of the interaction of silicic acid with aluminium in dilute solution and its biological significance. Inorganic Chimica Acta 153, 1-4.

Clarkson, E. M., Luck, V. A., Hynson, W. V., Bailey, R. R., Eastwood, J. B., Woodhead, J. S., Clements, V. R., O'Riordan, U. L. H. \& De Wardenerer, H. E. (1972). The effect of aluminium hydroxide on calcium, phosphorus and aluminium balances, the serum parathyroid hormone concentration and the aluminium content of bone in patients with chronic renal failure. Clinical Science 43, 519-531.

Clemente, F., Ribeiro, T., Figarella, C. \& Sarles, H. (1971). Albumine, IgG et IgA dans le suc pancreatique human normal chez l'adulte (Albumin, IgG and IgA in normal adult human pancreatic juice). Clinica Chimica Acta 33, 317-324.

Conrad, M. E. (1969). Humoral regulation of iron absorption. Gastroenterology 57, 225.

Conrad, M. E. \& Crosby, W. H. (1963). Intestinal mucosal mechanisms controlling iron absorption. Blood 22, 406-415.

Conrad, M. E., Umbreit, J. N. \& Moore, E. G. (1991). A role for mucin in the absorption of inorganic iron and other metal cations. Gastroenterology 100, 129-136.

Cook, J. D., Dassenko, S. A. \& Lynch, S. R. (1991). Assessment of the role of nonhaem-iron availability in iron balance. American Journal of Clinical Nutrition 54, 717-722.

Corain, B., Langato, B., Sheikh-Osman, A. A., Bombi, G. G. \& Macca, C. (1992). Aluminium carboxylates in aqueous solutions. Part 2. Metal speciation in the $\mathrm{Al}^{\mathrm{II}}$ lactate-OH- $\mathrm{H}_{2} \mathrm{O}$ system. Journal of the Chemical Society, Dalton Transactions 1, 169-172.

Crapper-McLachlan, D. R., Kruck, T. P., Lukin, W. J. \& Krishnan, S. S. (1991). Would decreased aluminium ingestion reduce the incidence of Alzheimer's disease? Canadian Medical Association Journal 145, $793-804$.

Crowther, R. S. \& Marriott, C. (1984). Counter-ion binding to mucus glycoproteins. Journal of Pharmacy and Pharmacology 36, 21-26.

Day, J. P., Barker, L., Evans, L. J. A., Perks, J., Seabright, P. J., Ackrill, P., Lilley, J. S., Drumm, P. V. \& Newton, G. W. A. (1991). Aluminium absorption studied by ${ }^{26} \mathrm{Al}$ tracer. Lancet i, 1345.

Dipaola, C. \& Mandel, I. D. (1980). Lactoferrin concentration in human parotid saliva as measured by an enzyme-linked immunosorbent assay (ELISA). Journal of Dental Research 59, 1463-1465.

Disler, P. B., Lynch, S. R., Charlton, R. W., Torrance, J. D., Bothwell, T. H., Walker, R. B. \& Mayet, F. (1975). The effect of tea on iron absorption. Gut 16, 193-200.

Domingo, J. L., Gomez, M., Llobet, J. M. \& Corbella, J. (1991a). Influence of some dietary constituents on aluminium absorption and retention in rats. Kidney International 39, 598-601.

Domingo, J. L., Gomez, M., Llobet, J. M. \& Richart, C. (1991b). Effect of ascorbic acid on gastrointestinal aluminium absorption. Lancet ii, 1467.

Erdman, J. W. \& Poneros-Schneier, A. (1989). Phytic acid interactions with divalent cations in foods and in the gastrointestinal tract. In Advances in Experimental Medicine and Biology, vol. 249, Mineral Absorption in the Monogastric GI Tract, pp. 161-171 [F. R. Dintzis and J. A. Laszlo, editors]. New York: Plenum Press.

Fairweather-Tait, S. J., Piper, Z., Jemil, S., Fatemi, A. \& Moore, G. R. (1991). The effect of tea on iron and aluminium metabolism in the rat. British Journal of Nutrition 65, 61-69.

Farrar, G., Morton, A. P. \& Blair, J. A. (1988). The intestinal speciation of gallium: possible models to describe the bioavailability of aluminium. In Trace Element Analytical Chemistry in Medicine and Biology, vol. 5. Proceedings of the Fifth International Workshop [P. Bratter and P. Schramel, editors]. Berlin: Walter de Gruyter.

Feinroth, M., Feinroth, M. V. \& Berlyne, G. M. (1982). Aluminium absorption in the rat everted gut sac. Mineral and Electrolyte Metabolism 8, 29-35.

Fleming, L. W., Prescott, A., Stewart, W. K. \& Cargill, R. W. (1989). Bioavailability of aluminium. Lancet i, 433.

Froment, D. H., Buddington, B., Miller, N. L. \& Alfrey, A. C. (1989b). Effect of solubility on the gastrointestinal absorption of aluminium from various aluminium compounds in the rat. Journal of Laboratory and Clinical Medicine 114, 237-242.

Froment, D. H., Molitoris, B. A., Buddington, B., Miller, N. \& Alfrey, A. C. (1989a). Site and mechanism of enhanced gastrointestinal absorption of aluminium by citrate. Kidney International 36, 978-984.

Fulton, B. \& Jeffery, E. H. (1990). Absorption and retention of aluminium from drinking water. 1. Effect of citric and ascorbic acids on aluminium tissue levels in rabbits. Fundamental and Applied Toxicology 14, $788-796$. 
Goldshmid, T. \& Rubin, A. J. (1978). Aqueous chemistry and precipitation of aluminium phosphate. In Chemistry of Waste Water Technology, pp. 59-80 [A. J. Rubin, editor]. Michigan: Ann Arbor Science Publishers Inc.

Gollan, J. L., Davis, P. S. \& Deller, D. J. (1971). A radiometric assay of copper binding in biological fluids and its application to alimentary secretions in normal subjects and Wilson's disease. Clinica Chimica Acta 31, 197-204.

Gorsky, J. E., Dietz, A. A., Spencer, H. \& Osis, D. (1979). Metabolic balance of aluminium studied in six men. Clinical Chemistry 25, 1739-1743.

Greger, J. L. \& Baier, M. J. (1983). Excretion and retention of low or moderate levels of aluminium by human subjects. Food and Chemical Toxicology 21, 473-477.

Haram, E. M., Weberg, R. \& Berstad, A. (1987). Urinary excretion of aluminium after ingestion of sucralfate and an aluminium containing antacid in man. Scandinavian Journal of Gastroenterology 22, 615-618.

Hem, S. L. \& White, J. L. (1989). Pharmaceutical uses of aluminium. In Aluminium and Health: a Critical Review, pp. 257-282 [H. J. Gitelman, editor]. New York: Marcel Dekker Inc.

Kaehny, W. D., Hegg, A. P. \& Alfrey, A. C. (1977). Gastrointestinal absorption of aluminium from aluminium-containing antacids. New England Journal of Medicine 296, 1389-1390.

Kaye, M. \& Gagnon, R. (1985). Aluminium and phosphate: The double bind. American Journal of Kidney Diseases 6, 365-367.

Koch, K. R., Pougnet, M. A. B., De Villiers, S. \& Monteagudo, F. (1988). Increased urinary excretion of Al after drinking tea. Nature 333, 122.

Kratzer, F. H. \& Vohra, P. (1986). Consideration of specific chelating agents: role of phytic acid and other phosphates as chelating agents. In Chelates in Nutrition, pp. 49-61. Boca Raton, Florida: CRC Press.

Lindholm, T., Thysell, H., Ljunggren, L., Divino, J. C., Schunnesson, M. \& Stenstam, M. (1985). Aluminum in patients with uremia and patients with enteropathy. Nieren-und Hochdruckkrankheiten 12, $192-197$.

Liu, J. C., Feldkamp, J. R., White, J. L. \& Hem, S. L. (1984). Adsorption of phosphate by aluminium hydroxycarbonate. Journal of Pharmaceutical Sciences 73, 1355-1358.

Lote, C. J. \& Saunders, H. (1991). Aluminium: gastrointestinal absorption and renal excretion. Clinical Science 81, 289-295.

MacDermott, R. P. \& Greenberger, N. J. (1969). Evidence for a humoral factor influencing iron absorption. Gastroenterology 57, 117-125.

MacDonald, T. L. \& Martin, R. B. (1988). Aluminium ion in biological systems. Trends in Biological Sciences 13, 15-19.

Magnusson, M., Magnusson, K. E., Sundqvist, T. \& Denneberg, T. (1991). Impaired intestinal barrier function measured by differently sized polyethylene glycols in patients with chronic renal failure. $G u t 32$, $754-759$

Martyn, C. N., Osmond, C., Edwardson, J. A., Barker, D. J. P., Harris, E. C. \& Lacey, R. F. (1989). Geographical relation between Alzheimer's disease and aluminium in drinking water. Lancet $\mathbf{i}, 59-62$.

Mauras, Y., Renier, J. C., Tricard, A. \& Allain, P. (1983). Mise en evidence de l'absorption gastro-intestinale du silicium a partir d'un alumino-silicate (Evidence for the gastrointestinal absorption of silicon from an aluminosilicate). Therapie 38, 175-178.

Menendez, M. J. F., Fell, G. S., Brock, J. H. \& Cannata, J. B. (1991). Aluminium uptake by intestinal cells: effect of iron status and precomplexation. Nephrology Dialysis Transplantation 6, 672-674.

Nicolai, J. J., Teunen, A., Zuyderhoudt, F., Hock, F. \& Tytgat, G. N. J. (1984). Lactoferrin in pure pancreatic juice. Scandinavian Journal of Gastroenterology 19, 765-769.

Nwokolo, C. U., Gavey, C. J., Smith, J. T. L. \& Pounder, R. E. (1989). The absorption of bismuth from oral doses of tripotassium dicitrato bismuthate. Alimentary Pharmacology and Therapeutics 3, 29-39.

Nwokolo, C. U., Lewin, J. F., Hudson, M. \& Pounder, R. E. (1992). Transmucosal penetration of bismuth particles in the human stomach. Gastroenterology 102, 163-167.

O'Hagan, D. T. (1990). Intestinal translocation of particulates - implications for drug and antigen delivery. Advanced Drug Delivery Reviews 5, 265-285.

Ohman, L. O. \& Sjoberg, S. (1988). Thermodynamic calculations with special reference to the aqueous aluminium system. In Metal Speciation: Theory, Analysis and Application, pp. 1-40 [J. R. Kramer and H. E. Allen, editors]. Chelsea, Michigan: Lewis Publishers.

Oppenheim, F. G. (1970). Preliminary observations on the presence and origin of serum albumin in human saliva. Helvetica Odontologica Acta 14, 10-17. 
Partridge, N. A., Reigner, F. E., White, J. L. \& Hem, S. L. (1989). Influence of dietary constituents on intestinal absorption of aluminium. Kidney International 35, 1413-1417.

Piper, D. W., Fenton, B. H. \& Goodman, L. R. (1967). Lactic, pyruvic, citric and uric acid and urea content of human gastric juice. Gastroenterology 53, 42-48.

Powell, J. J., Ainley, C. C., Kendall, M. D., Dhillon, A. P., Sankey, E. A. \& Thompson, R. P. H. (1991). Specific inorganic microparticles in gut tissue may initiate Crohn's disease. Gut 32, A572-A573.

Powell, J. J., Gartland, K. P. R., Nicholson, J. K., Ainley, C. C. \& Thompson, R. P. H. (1990). Bile, pancreatic juice, and small bowel secretions contain endogenous metal binding ligands. Gut 31, A1197.

Powell, J. J. \& Thompson, R. P. H. (1990). Aluminium deposition in bone after contamination of drinking water supply. Lancet ii, 888.

Provan, S. D. \& Yokel, R. A. (1988). Aluminium uptake by the in situ rat gut preparation. Journal of Pharmacology and Experimental Therapeutics 245, 928-931.

Quarterman, J. (1987). Metal absorption and the intestinal mucus layer. Digestion 37, 1-9.

Quarterman, J. \& Morrison, J. N. (1985). Heavy metal absorption stimulated by lactoferrin. In Trace Elements in Man and Animals 5, pp. 431-434 [C. F. Mills, I. Bremner and J. K. Chesters, editors]. Slough: Commonwealth Agricultural Bureaux.

Raja, K. B., Simpson, R. J. \& Peter, T. J. (1991). Ferric iron reduction and uptake by mouse duodenal mucosa. Biochemical Society Transactions 19, 316S.

Rodger, R. S. C., Muralikrishna, G. S., Halls, D. J., Henderson, J. B., Forrest, J. A. H., MacDougall, A. I. \& Fell, G. S. (1991). Ranitidine suppresses aluminium absorption in man. Clinical Science 80, 505-508.

Rudzki, Z., Baker, R. J. \& Deller, D. J. (1973). The iron-binding glycoprotein of human gastric juice II nature of the interaction of the glycoprotein with iron. Digestion 8, 53-67.

Sherlock, J. C. (1989). Aluminium in foods and the diet. In Aluminium in Food and the Environment, pp. 68-76 [R. C. Massey and D. Taylor, editors]. London: Royal Society of Chemistry

Slanina, P., Frech, W., Ekstrom, L., Loof, L., Slorach, S. \& Cedergren, A. (1986). Dietary citric acid enhances absorption of aluminium in antacids. Clinical Chemistry 32, 539-541.

Stewart, W. K. (1989). Aluminium toxicity in individuals with chronic renal disease. In Aluminium in Food and the Environment, pp. 7-19 [R. C. Massey and D. Taylor, editors]. London: Royal Society of Chemistry

Van der Voet, G. B. \& de Wolff, F. A. (1986). Intestinal absorption of aluminium in rats; effect of intraluminal $\mathrm{pH}$ and aluminium concentration. Journal of Applied Toxicology 6, 37-41.

Van der Voet, G. B. \& de Wolff, F. A. (1987). The effect of di- and trivalent iron on the intestinal absorption of aluminium in rats. Toxicology and Applied Pharmacology 90, 190-197.

Van der Voet, G. B., Van Ginkel, M. F. \& de Wolff, F. A. (1989). Intestinal absorption of aluminium in rats: stimulation by citric acid and inhibition by dinitrophenol. Toxicology and Applied Pharmacology 99, 90-97.

Walker, J. A., Sherman, R. A. \& Cody, R. P. (1990). The effect of oral bases on enteral aluminium absorption. Archives of Internal Medicine 150, 2037-2039.

Walters, C. B., Sherlock, J. C., Evans, W. H. \& Read, I. (1983). Dietary intake of fluoride in the United Kingdom and fluoride content of some foodstuffs. Journal of the Science of Food and Agriculture 34, 523-528.

Weaver, L. T., Laker, M. F. \& Nelson, R. (1984). Intestinal permeability in the newborn. Archives of Disease in Childhood 54, 236-241.

Weberg, R. \& Berstad, A. (1986). Gastrointestinal absorption of aluminium from single doses of aluminium containing antacids in man. European Journal of Clinical Investigation 16, 428-432. 